\title{
Metastatic Hemangiopericytoma Presenting as an Epidural Spinal Cord Lesion
}

\author{
Steven David Brass, Marie-Christine Guiot, Steffen Albrecht, Rafael Glikstein, \\ Gérard Mohr
}

\begin{abstract}
Objective: Hemangiopericytoma is an aggressive vascular tumour that rarely affects the central nervous system and is even more rarely spinal in presentation. The clinical features of a patient with a recurrent extraspinal hemangiopericytoma presenting with an epidural spinal cord compression by local invasion are described, including a review of the literature on metastatic hemangiopericytoma to the spine. Methods: A case of a 53-year-old male, with a recurrent extraspinal hemangiopericytoma which metastasized to the thoracic spine five years after detection of the primary tumour is presented. A chart review was conducted where all pertinent history, physical, laboratory, and radiological data were collected. A Pub-Med search using the keyword "hemangiopericytoma" identified all reported cases documenting clinical features, treatment, recurrence and outcome with respect to metastatic hemangiopericytoma to the spine. Results: Nine patients have been reported to have metastatic hemangiopericytoma to the spine. The median patient age was 47 years and there was a slight male preference. An unusual feature of the hemangiopericytoma is the prolonged period, up to 16 years, between the diagnosis of the primary hemangiopericytoma and the metastases to the spine. All patients were treated with a combination of radiation and surgery. Conclusion: Hemangiopericytomas show a slow clinical evolution with a strong propensity to relapse long after previous treatment and thus, once identified, prolonged follow-up for recurrence is indicated. A close follow-up of these patients is required because of frequent recurrences and delayed metastases even if the primary lesion was well-controlled. Although overall uncommon, hemangiopericytoma should be kept in mind in the differential diagnosis of vascular epidural spinal cord tumours.
\end{abstract}

RÉSUMÉ: Hémangiopéricytome métastatique dont le tableau initial était celui d'une lésion épidurale de la moelle épinière. Objectif: L'hémangiopéricytome est une tumeur vasculaire agressive qui atteint rarement le système nerveux central et encore plus rarement la moelle épinière. Nous décrivons le tableau clinique d'un patient atteint d'un hémangiopéricytome extraspinal récidivant qui a consulté pour un syndrome de compression de la moelle épinière par envahissement local et nous révisons la littérature concernant l'hémangiopéricytome métastatique à la moelle épinière. Méthodes : Nous présentons un cas d'hémangiopéricytome extraspinal récidivant chez un patient âgé de 53 ans avec métastase à la moelle épinière thoracique cinq ans après la découverte de la tumeur primitive. Les données du dossier clinique concernant l'histoire médicale pertinente, l'examen physique et les examens de laboratoire et de radiologie de notre patient sont présentés, ainsi que le tableau clinique, le traitement, la récidive et l'issue de l'hémangiopéricytome métastatique à la moelle épinière de tous les cas rapportés dans la littérature médicale, identifiés par une recherche Pub-Med utilisant le mot-clé « hémangiopéricytome ». Résultats : Neuf patients ayant un hémangiopéricytome avec métastases à la moelle épinière ont été rapportés. L'âge médian des patients était de 47 ans et il y avait un peu plus d'hommes que de femmes. Une caractéristique inusitée de ces lésions est l'intervalle très long entre le diagnostic de la tumeur primitive et les métastases à la moelle épinière, soit jusqu'à 16 ans. Tous les patients ont été traités par radiothérapie associée à la chirurgie. Conclusion : L'évolution clinique de l'hémangiopéricytome est lente avec une forte tendance à récidiver longtemps après le traitement de la lésion initiale, même si celle-ci était sous contrôle. Ces patients doivent donc être suivis de près à long terme. Bien qu'il soit rare, l'hémangiopéricytome doit faire partie du diagnostic différentiel des tumeurs vasculaires de la moelle épinière.

Can. J. Neurol. Sci. 2004; 31: 550-553

Primary hemangiopericytoma is a rare vascular tumour that may occur anywhere in the body but the most frequently reported primary locations are the lungs, the bones, the meninges, the kidneys, the liver and skin. ${ }^{1}$ Zimmerman in 1923 first described the cells on the surface of capillaries and named them pericytes. ${ }^{2}$ In 1942, Stout and Murray coined the term "hemangiopericytoma" after reporting nine cases of tumours characterized by many capillaries surrounded by packed cells of indeterminate origin. $^{2}$

Although uncommon, hemangiopericytoma may affect the spine. Hemangiopericytoma has been described to involve the spine in three ways: (1) intradural hemangiopericytoma; (2) intra- spinal extradural meningeal hemangiopericytoma/primary osseous hemangiopericytoma; and (3) metastatic hemangiopericytoma to the spine. ${ }^{1}$ In this report, the clinical features of a

From the Department of Neurology, Harvard University, Brigham and Women's Hospital, Boston, MA, USA(SDB); Department of Neuropathology, McGill University, Montreal Neurological Hospital, (M-CG); McGill University, Sir Mortimer B. Davis-Jewish General Hospital, Department of Pathology (SA); Department of Neuroradiology (RG); Department of Neurorosurgery (GM), Montreal, Quebec Canada. ReCeived December 2, 2003. ACCEPTED INFINALForm APRIL 13, 2004.

Reprint requests to: Gérard Mohr, Division of Neurosurgery, Sir Mortimer B. DavisJewish General Hospital, 3755 Chemin de la Côte Ste. Catherine, Montreal, H3T1E2, Quebec Canada. 

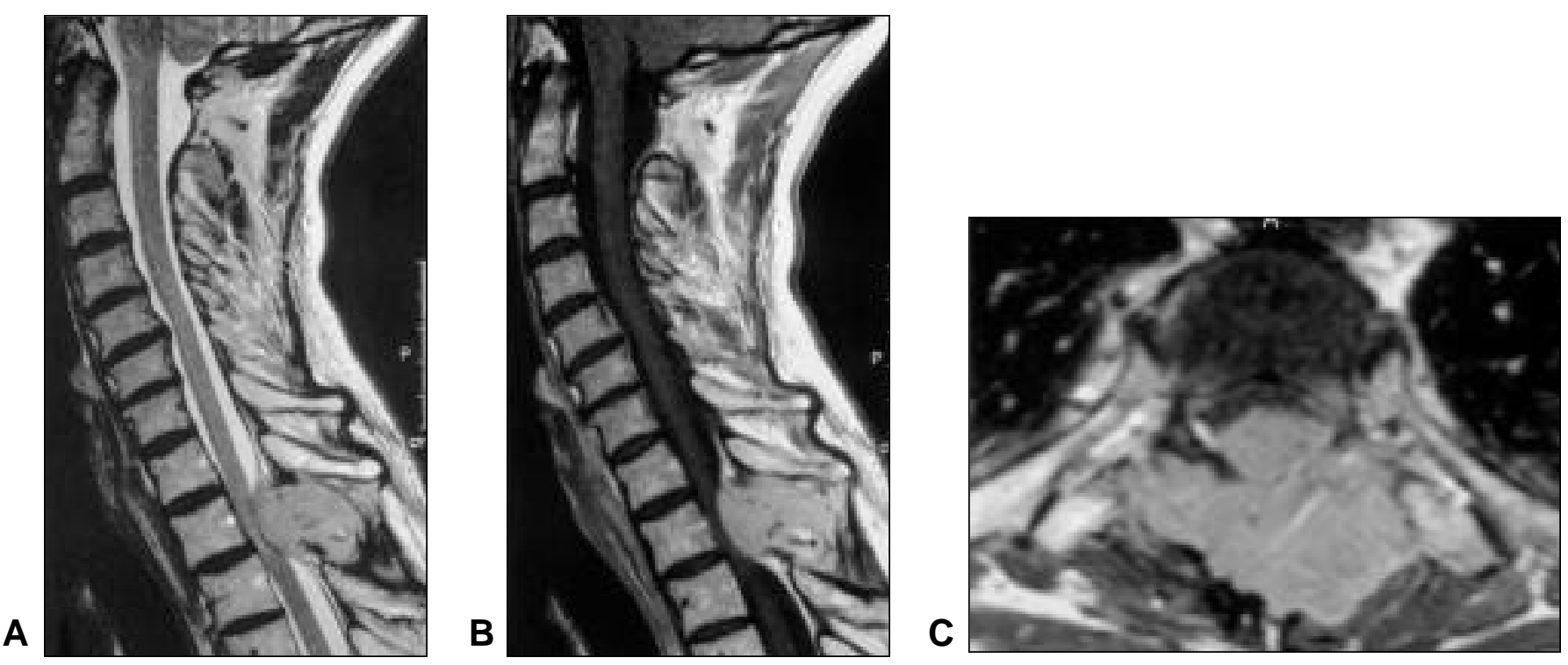

Figure 1: (A) Sagital T2-weighted MRI of the spine demonstrating a slightly hyperintense lesion with cord compression. The posterior ligament is pushed anteriorly

(B) Sagital T1-weighted post-gadolinium MRI reveals enhancing mass lesion causing cord compression. Note the multiple round and oval tubular shaped flow void signals representing abnormal vessels compatible with a hypervascular lesion.

(C) Axial T1-weighted post-gadolinium MRI reveals a large heterogeneous enhancing mass in the posterior paravertebral tissues extending to the epidural space compressing the cord. There is destruction of the T2 vertebral body.

patient with a recurrent extraspinal paravertebral hemangiopericytoma which metastasized to the epidural spinal cord by local invasion five years after detection of the primary tumour are presented. The overall objective of this report is to better characterize this uncommon pathology by reviewing its clinical, histological, and radiological features. The importance of recognizing this pathology lies in the fact that the vascular features and aggressive nature of this tumour may complicate pre-operative assessment, treatment and long-term follow-up given the propensity to relapse and spread as in this case, despite a prolonged interval of time after detection and treatment of the primary tumour.

\section{Case Report}

A 53-year-old right-handed Caucasian male presented to the emergency department with a three week history of continuous intrascapular pain worsened by the supine position. One week prior to presentation, he developed a band-like sensation around his entire thorax. He denied focal weakness, bowel or bladder symptoms. The neurological exam demonstrated a thin male with a myelopathic clinical picture. The upper extremities were normal. However, the lower extremities demonstrated spasticity with preserved strength. His reflexes were $4+$ in the lower limbs with bilateral extensor plantar responses. The sensory exam revealed a T4 sensory level to pinprick and absent vibration with preserved proprioception in the feet. His gait and coordination examination was normal.

The patient's past medical history was significant for presenting with a painless mass in his back five years prior. At that time a $15 \mathrm{~cm}$ lesion was detected, invading the back musculature over the lower cervical and upper thoracic spine extending into the spinous processes. This was resected and shown to be a primary Grade II hemangiopericytoma. ${ }^{2}$ Following surgery; the patient had postoperative conformal radiation therapy. He recovered without neurological complaints and was later lost to follow-up. Family history was noncontributory.

Laboratory work included a normal complete blood count, biochemistry, coagulation studies, prostate specific antigen and liver function tests. Magnetic resonance imaging (MRI) was performed and confirmed the extradural vascular tumour compressing the spinal cord at the T2-T3 level (Figure 1). There was no evidence of remote metastases present in the lungs or abdominal cavity based on CT images and ultrasound examination, respectively. An initial surgical attempt was made at resection but due to the significant vascular nature of the lesion the surgery was stopped. Some decompression was achieved. Histology revealed a Grade II hemangiopericytoma (Figure 2). Four days later a spinal angiogram with embolization of the T3 radicular artery was obtained (Figure 3). One day after embolization, a second surgical resection was attempted, however intraoperative bleeding became significant and uncontrollable and the surgery was again aborted. Postoperatively, he was treated with focused external beam radiation therapy to the T2 and T3 area. Due to the extensive cutaneous defect secondary to wound dehiscence, he required a right latissimus dorsi free-flap with a skin graft to cover the surgical wound. Despite the failure of total resection, the patient's neurological symptoms improved and he walked independently on discharge from the hospital.

He was readmitted one year later to the Oncology service with a subacute paraparesis and back pain progressive over a month. An MRI of the spine revealed enlargement of the tumour with greater spinal cord compromise. As rescue therapy, the attending Oncologist treated this patient with one cycle of cisplatin, ifosfamide and gemcitabine based on a previous marked response reported in the Japanese literature for a case of lung hemangiopericytoma. ${ }^{3}$ No improvement was made and ultimately there was progression as the bowel and bladder symptoms worsened. The patient was discharged home after a three-month hospital course with home care. Two years later, after discharge from the 


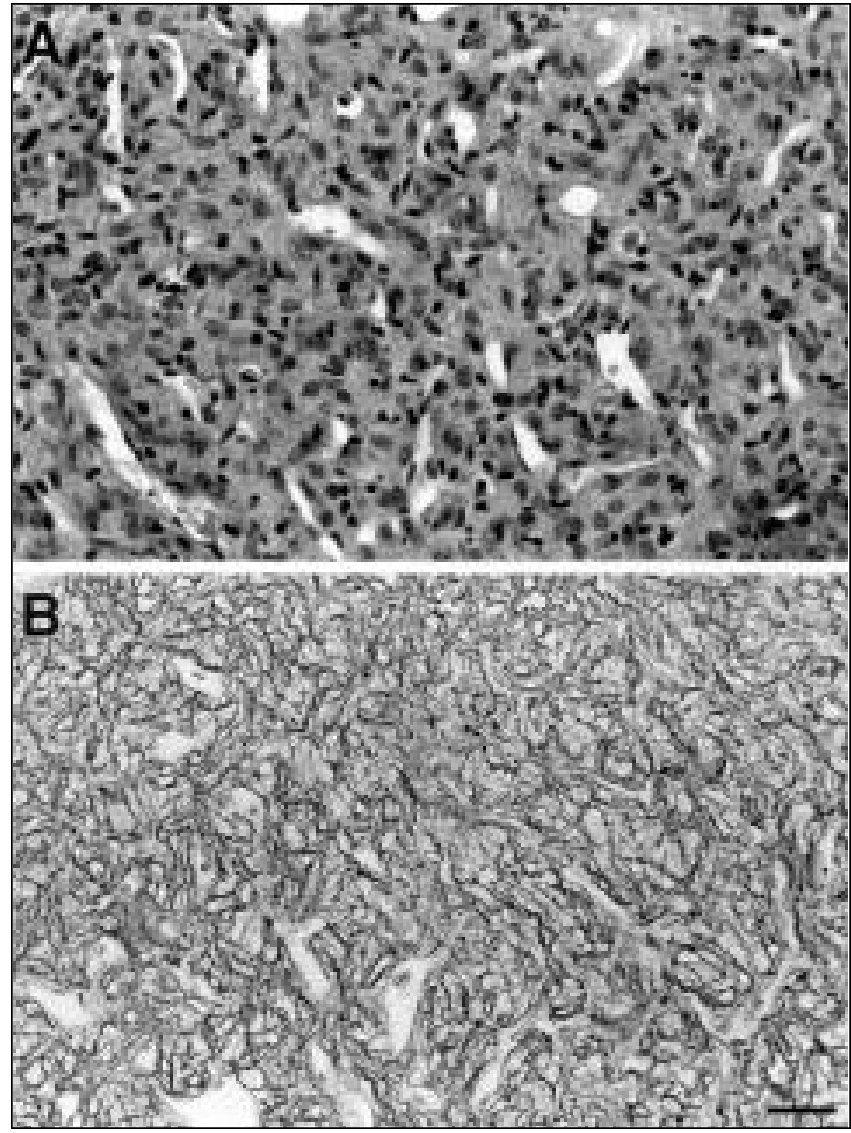

Figure 2: Histological features of hemangiopericytoma: (A) H\&E stain, high cellularity and staghorn vessels. (B) Reticulin stain, dense reticulin network surrounding individual cells. Magnification $x 800$, scale: $1 \mathrm{~cm}=$ 12.5 microns.

Oncology department, he remains stable with a complete sensory-motor paralysis and a T4 sensory level. There was no further evidence of any progression of disease based on imaging and clinical exam.

\section{Discussion}

Hemangiopericytoma is a soft tissue tumour consisting of a vascular and cellular component. The vascular component is composed of capillaries with endothelial cells and a normal basement membrane. ${ }^{3}$ The cellular component of the tumour constitutes the actual growth and is made up of neoplastic spindle-shaped cells derived from Zimmerman pericytes that are grouped in cords. Hemangiopericytoma is considered to be an aggressive tumour due to its strong tendency to both locally recur and metastasize. The local recurrence rate from series of hemangiopericytomas is between 50-80 percent and the literature reports rates of metastasis ranging from $23-78$ percent. $^{1}$ This case represents a patient with a recurrent extraspinal hemangiopericytoma that extended to cause thoracic epidural spinal cord compression after an initial resection of a cervicothoracic muscular paravertebral hemangiopericytoma five years earlier.

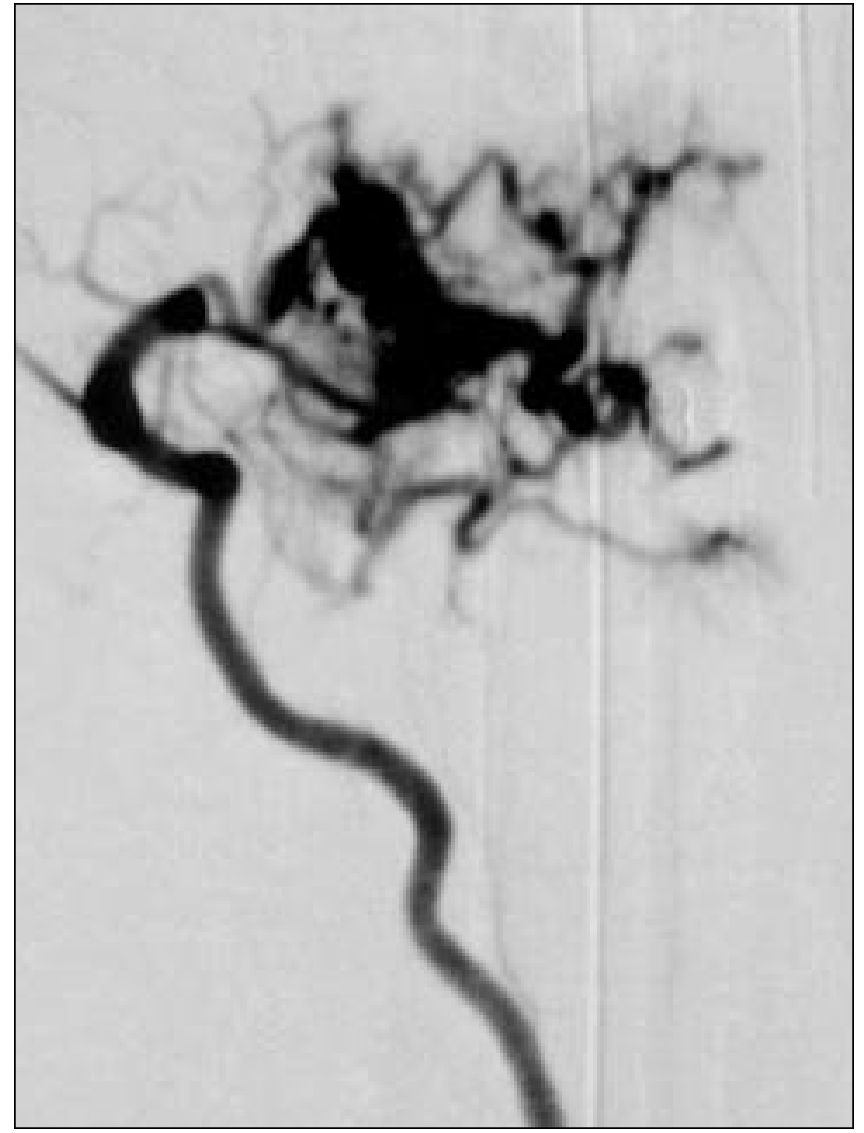

Figure 3: Spinal angiogram demonstrating tortuous vessels with an early blush.

There are limited MRI descriptions of spinal hemangiopericytomas in the literature. MRI is not specific but may provide findings consistent with a diagnosis of hemangiopericytoma. The important feature which helps support the radiological diagnosis of hemangiopericytoma is the hypervascular nature of the tumour. ${ }^{5,6}$ The MR images of the spine demonstrate an epidural mass with linear hypointense signals that enhanced heterogeneously with contrast administration. Computerised tomography findings may demonstrate dural attachment and destruction of adjacent bone without calcification with intense contrast enhancement. The lack of calcification may help separate hemangiopericytoma from meningiomas, which may often have a spinal presentation with bony involvement. ${ }^{5,6}$ In considering the differential diagnosis of an extradural vascular spinal lesion on MR imaging, one needs to include other hypervascular pathologies such as metastases of renal cell carcinoma and mesenchymal tumours, i.e. chordomas. The procedure most helpful in supporting a diagnosis of hemangiopericytoma is spinal angiography, which demonstrates a highly vascularized tumour. ${ }^{5,6}$

On reviewing the literature of metastatic hemangiopericytoma to the spine, the rarity of this disorder is apparent, with 
only nine cases (including this case) reported to date ${ }^{1,7-12}$ The median patient age was 47 years (range: 22 to 56 years). The male to female ratio was 5 to 4 . Among 4/9 cases reported, the primary hemangiopericytoma was localized most often to the intracranial meninges; other sites being the heart, the arm, the groin and the lung. ${ }^{1,13}$ Spinal metastases were localized in 5/9 cases to the thoracic area, in 5/9 cases to the lumbar area, and in 2/9 cases to the cervical area. ${ }^{1}$ The clinical history and physical exam were typical for either a myelopathy or a radiculopathy on initial presentation. All patients were treated with a combination of surgery decompression and radiation therapy. Hemangiopericytomas show a slow clinical evolution with a strong propensity to relapse. The mean time for the tumour to metastasize to the spine was five years, with a range from 0 to 16 years. There was too much variability in both the follow-up times post therapy and documented outcomes when available among the nine cases making it difficult to make a generalization with respect to long term prognosis for metastatic spinal hemangiopericytoma.

This uncommon pathology, when added to the previous reports in the literature, further characterizes the clinical features of metastatic spinal hemangiopericytoma and the MRI features of this tumour. While the incidence of this tumour is rare, it must be included in the differential diagnosis of lesions causing epidural spinal cord compression. Due to its extreme vascularity, the high risk of intraoperative hemorrhage should be anticipated at surgery even despite reports of success with preoperative embolization. ${ }^{14}$ A close follow-up of these patients is required because of frequent recurrences and delayed metastases even if the primary lesion was well-controlled. Although no randomized controlled treatment trials exist for the treatment of metastatic hemangiopericytoma to the spine, complete surgical resection and postoperative radiotherapy appears to be the treatment of choice. ${ }^{5,15}$ The role of chemotherapy still remains unanswered to date.

\section{REFERENCES}

1. Woitzik J, Sommer C, Krauss JK. Delayed manifestation of spinal metastasis: a special feature of hemangiopericytoma. Clin Neurol Neurosurg 2003;105:159-166.

2. Stout AP, Murray MR. Hemangiopericytoma: vascular tumour featuring Zimmerman's pericytes. Ann Surg 1942;116:26-33.

3. Weiss SW, Sobin LH. Histologic Typing of Soft Tissue Tumours, 2nd ed. Berlin, Springer-Verlag, 1994.

4. Fujita A, Minase T, Takabatake H, Tagaki S, Sekine K. A case of primary malignant hemangiopericytoma of the lung with marked response to combination chemotherapy with cisplatin, ifosfamide and gemcitabine. Gan to Kagaku Ryoho. 2001;28:373-376.

5. Lin YJ, Tu YK, Lin SM, Shun CT. Hemangiopericytoma in the axis bone: case report and review of the literature. Neurosurgery 1996;39:397-399.

6. Osborne DR, Dubois P, Drayer B, et al. Primary intracranial meningeal and spinal hemangiopericytomas. Radiological manifestations. AJNR Am J Neuroradiol 1981;2:69-74.

7. Kruse F. Hemangiopericytoma of the meninges (angioblastic meningioma of Cushing and Eisenhardt). Neurology 1961;11:771-777.

8. Harris MG, Fournaiser VL, Livingston KE. Hemangiopericytoma of the spinal canal; report of three cases. J Neurosurg 1978;49:914920.

9. Scott M, Kellett G, Peale A. Angioblastic meningioma (hemangiopericytoma) of the cerebellar fossa with metastases to the temporal bone and the lumbar spine. Surg Neurol 1974;2:3538.

10. Mao P, Angrist A. Hemangiopericytoma of the heart with metastasis to vertebra. Arch Pathol 1967;83:466-470.

11. Hansen CP, Francis D, Bertelsen S. Primary hemangiopoericytoma of the lung. Case report. Scand J Thorac Cardiovac Surg 1990;24:89-92.

12. Nonaka M,Kohmura E, Hirata M, Hayakawa T. Metastatic meningeal hemangiopericytoma of thoracic spine. Clin Neurol Neurosurg 1998;100:228-230.

13. Hermann HD, Hess H, Kridde OE. Hemangiopericytoma of the arm, vertebral metastasis and transverse syndrome. Arch Orthop Unfallchir 1968;63:267-272.

14. Muraszko KL, Antunes JL, Hilal SK, Michelsen WJ. Hemangiopericytoma of the spine. Neurosurgery 1982;10:473-479.

15. Stern MB, Grode ML, Goodman MD. Hemangiopericytoma of the cervical spine: report of an usual case. Clin Orthop Rel Res 1980;151:201-204. 